\title{
The prognostic and predictive value of the 8th American Joint Committee on Cancer (AJCC) staging system among early breast cancer patients aged $<50$ years
}

\author{
Jun Wang ${ }^{1 \#}$, Chen-Lu Lian ${ }^{1 \#}$, Ping Zhou ${ }^{1}$, Jian Lei $^{2}$, Li Hua ${ }^{2}$, Zhen-Yu He ${ }^{3}$, San-Gang Wu ${ }^{1}$ \\ ${ }^{1}$ Department of Radiation Oncology, the First Affiliated Hospital of Xiamen University, Xiamen, China; ${ }^{2}$ Department of Obstetrics and Gynecology, \\ the First Affiliated Hospital of Xiamen University, Xiamen, China; ${ }^{3}$ Department of Radiation Oncology, Sun Yat-sen University Cancer Center, State \\ Key Laboratory of Oncology in South China, Collaborative Innovation Center of Cancer Medicine, Guangzhou, China \\ Contributions: (I) Conception and design: SG Wu, J Wang, CL Lian, ZY He; (II) Administrative support: SG Wu, J Wang; (III) Provision of study \\ materials or patients: SG Wu; (IV) Collection and assembly of data: SG Wu, ZY He; (V) Data analysis and interpretation: P Zhou, J Lei, L Hua; (VI) \\ Manuscript writing: All authors; (VII) Final approval of manuscript: All authors. \\ \#These authors contributed equally to this work. \\ Correspondence to: Zhen-Yu He. Department of Radiation Oncology, Sun Yat-sen University Cancer Center, State Key Laboratory of \\ Oncology in South China, Collaborative Innovation Center of Cancer Medicine, 651 Dongfeng Road East, Guangzhou 510060, China. \\ Email: hezhy@sysucc.org.cn; San-Gang Wu. Department of Radiation Oncology, the First Affiliated Hospital of Xiamen University, Teaching \\ Hospital of Fujian Medical University, Xiamen 361003, China. Email: wusg@xmu.edu.cn.
}

Background: This study respectively analyzed the prognostic value and the role in treatment decisionmaking [breast-conserving surgery (BCS) + radiotherapy (RT) or mastectomy (MAST)] of the 8th American Joint Committee on Cancer (AJCC) pathological prognostic staging system compared with the 7th AJCC anatomical staging system among early breast cancer patients aged $<50$ years.

Methods: Patients with T1-2N0M0 breast cancer aged $<50$ years were extracted from the Surveillance, Epidemiology, and End Results database between 2010 and 2014. Breast cancer-specific survival (BCSS) was used as the primary endpoint. Chi-squared test, receiver operating characteristics analysis, Kaplan-Meier method, and multivariate Cox proportional models were used to conduct statistical analysis.

Results: A total of 22,640 female patients were identified, and 24.4\% of them reallocated to new stage groups from the 7 th to the 8 th AJCC staging. Among them, 46.2\% $(n=10,450)$ and $53.8 \%(n=12,190)$ of patients received BCS + RT and MAST, respectively. The 8th AJCC staging system was an independent prognostic factor for BCSS. Patients treated with BCS + RT had better BCSS compared to those treated with MAST $(\mathrm{P}<0.001)$. According to the 8th AJCC staging, BCS + RT could improve 5-year BCSS compared with MAST in patients with stage IA $(\mathrm{P}=0.006)$ and stage IB $(\mathrm{P}=0.001)$ diseases, while comparable BCSS was found between the two treatment arms in patients' stage IIA disease $(\mathrm{P}=0.366)$. Multivariate analyses replicated similar findings after stratification by the 8th AJCC stages.

Conclusions: In patients with T1-2N0 breast cancer and aged <50 years, the 8th AJCC pathological staging system provides accurate prognostic information than the 7 th anatomical staging. BCS + RT is the optimal local management for stage IA and IB diseases, while it is the optional management in stage IIA disease according to the 8th AJCC staging.

Keywords: Breast cancer; breast-conserving surgery (BCS); mastectomy (MAST); radiotherapy (RT); American Joint Committee on Cancer staging system (AJCC staging system)

Submitted Jul 01, 2020. Accepted for publication Nov 11, 2020.

doi: $10.21037 /$ gs-20-587

View this article at: http://dx.doi.org/10.21037/gs-20-587 


\section{Introduction}

Breast cancer is a malignant disease with the highest prevalence and the leading cause of cancer death in women. Approximately 2 million women were newly diagnosed with breast cancer, and 630,000 died from breast cancer in 2018 worldwide (1). Patients with early breast cancer, especially T1-2 (tumor size $\leq 5 \mathrm{~cm}$ ) and negative axillary lymph nodes (N0), were increasingly diagnosed due to the early detection by mammographic screening (2). In the current clinical practice, breast-conserving surgery (BCS) + adjuvant radiotherapy (RT) or mastectomy (MAST) was the optional locoregional management for patients with early breast cancer (3).

The traditional American Joint Committee on Cancer (AJCC) staging system has been widely used for prognosis predicting and treatment decision-making in breast cancer, which was based on anatomic information including tumor size, lymph node status, and distant metastasis (4). Considering the remarkable progress and importance of biologic markers such as histological grade, estrogen receptor (ER), progesterone receptor (PR), and human epidermal growth factor-2 (HER2) in breast cancer, the 8th AJCC staging system incorporated indicators mentioned above to better distinguish the prognosis of breast cancer patients $(5,6)$. However, the effect of the 8th AJCC staging system on surgical decision-making remains unclear in breast cancer. Previous trials have demonstrated BCS + $\mathrm{RT}$ achieved at least equivalent survival compared with MAST in patients with T1-2N0 breast cancer based on the 7th AJCC staging criterion (7-14). However, whether the results were still applicable based on the new staging system was not well elaborated.

Several studies have shown a higher local recurrence rate and inferior overall survival in patients aged $<50$ years compared to those aged $\geq 50$ years $(15,16)$. In the current clinical practice, approximately $50-63 \%$ of the patients aged $<50$ years opted for the MAST procedure $(17,18)$. However, the impact of surgical approaches on the survival of breast cancer patients with a younger age has yielded conflicting results $(19,20)$. The study from Laurberg et al. showed that younger patients with BCS + RT had higher local recurrence risk and mortality than those with MAST (19), while comparable survival was found between BCS + RT and MAST in a systematic meta-analysis (20). Therefore, our study aimed to evaluate the prognostic value and the role in treatment decision-making (BCS + RT or MAST) of the 8th AJCC staging system compared with the 7th AJCC staging system among patients with early breast cancer aged $<50$ years.

We present the following article in accordance with the STROBE reporting checklist (available at http://dx.doi. org/10.21037/gs-20-587).

\section{Methods}

\section{Surveillance, Epidemiology, and End Results (SEER) database and patients}

The SEER database was utilized to extract the patient listing between 2010 and 2014. The SEER database collects data from 18 national cancer registries and captures $30 \%$ of the population in the United States, which consists of detailed information about demographics, tumor characteristics, intervention, and survival status in cancer patients (21).

Eligible patients were defined using the following criteria: (I) women with a definite pathological diagnosis of primary non-metastatic breast cancer and aged less than 50 years; (II) patients with stage T1-2N0M0 cancers; (III) knowing the status of ER, PR, HER2, and tumor grade; (IV) receiving BCS followed by postoperative RT or MAST alone. Criteria for study exclusions were as follows: (I) without a definite pathological diagnosis; (II) not receiving surgery procedures, receiving BCS without following RT, or receiving MAST followed by RT. The AJCC staging systems were based on the 7 th edition of the AJCC anatomical staging and the 8th edition of the AJCC pathological prognostic staging. This study was exempted from the approval of the Institutional Review Board of the First Affiliated Hospital of Xiamen University due to the anonymous information in the SEER database. The study was conducted in accordance with the Declaration of Helsinki (as revised in 2013).

We collected the information of the following variables: age, race/ethnicity, tumor size, histological grade, hormone receptor status, HER2 status, surgery procedures, and RT administration. Breast cancer-specific survival (BCSS) was used as the primary endpoint in this study, which was measured from the date of diagnosis to the date of death from breast cancer.

\section{Statistical analysis}

All of the statistical analyses were conducted using the IBM SPSS Statistics (Version 22.0; IBM Corp., New 
Table 1 Demographics and clinical characteristics of the patients with T1-2N0 breast cancer aged $<50$ years $(n=22,640)$

\begin{tabular}{|c|c|c|c|}
\hline Variables & $\mathrm{BCS}+\mathrm{RT}(\%)$ & MAST (\%) & $\mathrm{P}$ \\
\hline Age (years) & & & $<0.001$ \\
\hline$<40$ & $1,320(12.6)$ & $2,803(23.0)$ & \\
\hline$\geq 40$ & $9,130(87.4)$ & $9,387(77.0)$ & \\
\hline Race/ethnicity & & & $<0.001$ \\
\hline Non-Hispanic White & $6,436(61.6)$ & $7,622(62.5)$ & \\
\hline Non-Hispanic Black & $1,231(11.8)$ & $1,200(9.8)$ & \\
\hline Hispanic & 1,384 (13.2) & $1,772(14.5)$ & \\
\hline Other & $1,399(13.4)$ & $1,596(13.1)$ & \\
\hline Grade & & & $<0.001$ \\
\hline Well differentiated & 2,783 (26.6) & 2,428 (19.9) & \\
\hline Moderately differentiated & $4,230(40.5)$ & $4,960(40.7)$ & \\
\hline $\begin{array}{l}\text { Poorly differentiated/ } \\
\text { undifferentiated }\end{array}$ & 3,437 (32.9) & $4,802(39.4)$ & \\
\hline T stage & & & $<0.001$ \\
\hline $\mathrm{T} 1$ & $7,852(75.1)$ & $8,242(67.6)$ & \\
\hline $\mathrm{T} 2$ & $2,598(24.9)$ & $3,948(32.4)$ & \\
\hline The 7th AJCC staging & & & $<0.001$ \\
\hline IA & $7,852(75.1)$ & $8,242(67.6)$ & \\
\hline IIA & $2,598(24.9)$ & $3,948(32.4)$ & \\
\hline The 8th AJCC staging & & & $<0.001$ \\
\hline IA & $8,321(79.6)$ & $9,113(74.8)$ & \\
\hline IB & $1,102(10.5)$ & $1,518(12.5)$ & \\
\hline IIA & $1,027(9.8)$ & $1,559(12.8)$ & \\
\hline ER status & & & $<0.001$ \\
\hline Negative & $1,743(16.7)$ & $2,619(21.5)$ & \\
\hline Positive & 8,707 (83.3) & $9,571(78.5)$ & \\
\hline PR status & & & $<0.001$ \\
\hline Negative & $2,281(21.8)$ & $3,448(28.3)$ & \\
\hline Positive & 8,169 (78.2) & $8,742(71.7)$ & \\
\hline HER2 status & & & $<0.001$ \\
\hline Negative & $9,104(87.1)$ & 9,995 (82) & \\
\hline Positive & 1,346 (12.9) & 2,195 (18) & \\
\hline
\end{tabular}

BCS, breast-conserving surgery; RT, radiotherapy; MAST, mastectomy; ER, estrogen receptor; PR, progesterone receptor; HER2, human epidermal growth factor receptor 2; AJCC, American Joint Committee on Cancer.
York, USA). Chi-square test was performed to analyze the clinicopathological characteristics, including age, race/ ethnicity, tumor size, histological grade, hormone receptor status, and HER2 status between BCS + RT and MAST groups. The receiver operating characteristics (ROC) curve was used to assess the discriminatory ability between the 7 th and the 8 th AJCC staging system in predicting survival outcome. Kaplan-Meier method was applied to draw survival curves to estimate the crude trend of BCSS. Multivariate Cox proportional hazards models were used to determine the potential confounding predictors for BCSS. A P value $<0.05$ (two-tail) was considered statistically significant.

\section{Results}

\section{Clinicopathological characteristics}

A total of 22,640 female patients were identified. Table 1 depicted the detailed information on patient demographics and tumor characteristics in this study. The mean age of diagnosis was 45 years (range, 18-49 years). Of the patients, $62.1 \%, 10.7 \%, 13.9 \%$, and $13.2 \%$ of them were non-Hispanic White, non-Hispanic Black, Hispanic, and other race/ethnicity, respectively. With regard to tumor characteristics, the majority of them were stage $\mathrm{T} 1$ disease (71.1\%), ER-positive (80.7\%), PR-positive (74.7\%), and HER2 negative (84.4\%).

In the entire cohort, $46.2 \%(\mathrm{n}=10,450)$ and $53.8 \%$ $(\mathrm{n}=12,190)$ of them were treated with BCS + RT and MAST, respectively. Patient treated with BCS + RT were more likely to be lower tumor grade $(\mathrm{P}<0.001)$, smaller tumor size $(\mathrm{P}<0.001)$, early-stage $(\mathrm{P}<0.001)$, ER-positive $(\mathrm{P}<0.001)$, $\mathrm{PR}$-positive $(\mathrm{P}<0.001)$, and HER2 negative $(\mathrm{P}<0.001)$ compared to those treated with MAST (Table 1).

\section{Restaging and ROC analysis}

Of the patients in this study, $71.1 \%(\mathrm{n}=16,094)$ and $28.9 \%$ $(\mathrm{n}=6,546)$ had traditional anatomical staging of IA and IIA, while $77.0 \%(\mathrm{n}=17,434), 11.6 \%(\mathrm{n}=2,620)$, and $11.4 \%$ $(n=2,586)$ of the patients were stage IA, IB, and IIA in the 8th staging, respectively. A total of $24.4 \%(n=5,517)$ of the patients reallocated to new stage groups. Among them, $6.9 \%(\mathrm{n}=1,557)$ upstaged from stage IA in the 7 th to stage IB in the 8th AJCC staging, $12.8 \%(n=2,897)$ downstaged from IIA to IA, and $4.7 \%(n=1,063)$ migrated from stage 


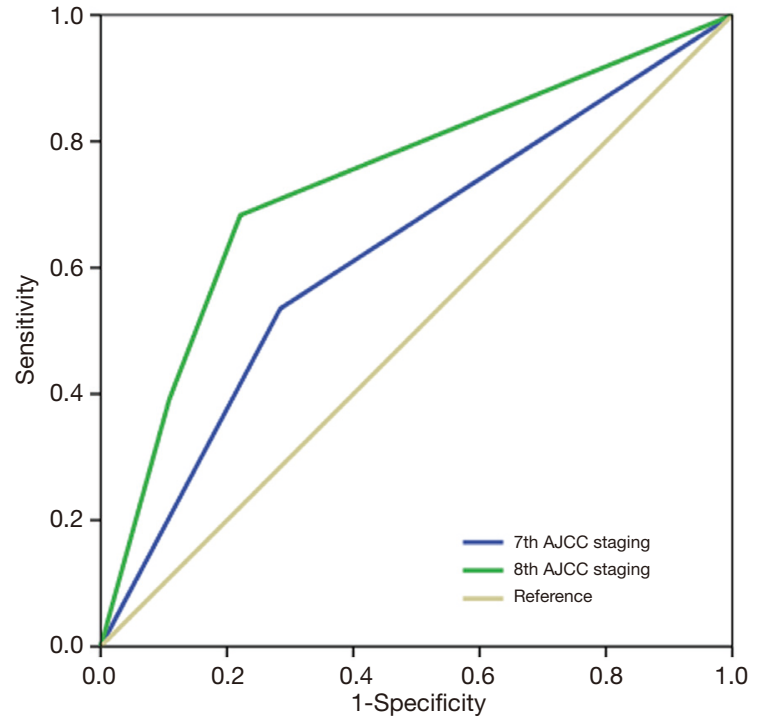

Figure 1 Receiver operating characteristics curve for predicting the breast cancer-specific survival between the 7 th and the 8 th American Joint Committee on Cancer staging system.

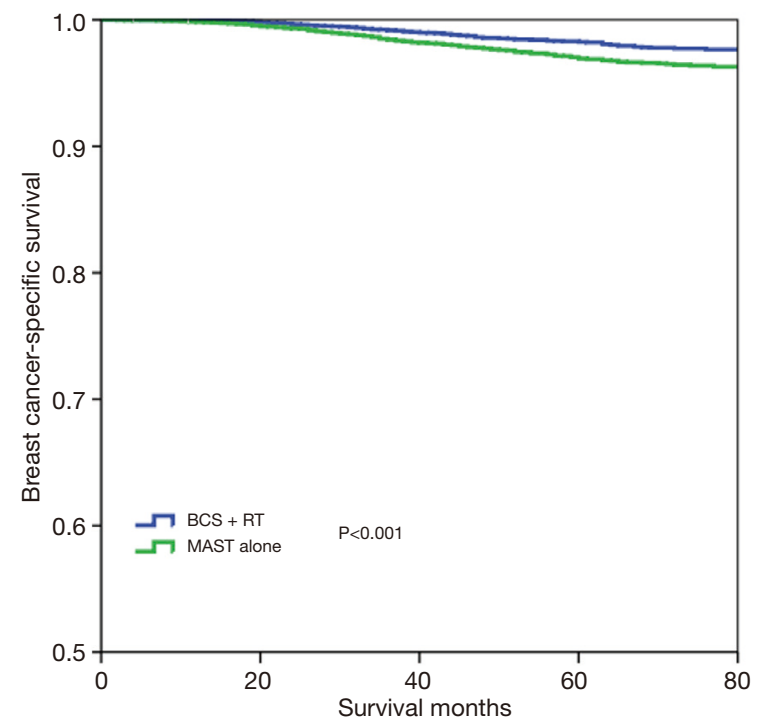

Figure 2 Survival curves between breast-conserving surgery (BCS) + radiotherapy (RT) and mastectomy (MAST) groups for the whole group.

IIA to stage IB. The ROC analysis demonstrated that the 8th AJCC staging [the area under the curve (AUC) 0.737, 95\% confidence interval (CI): 0.711-0.763] had the better discriminative ability to predict BCSS rate compared with the 7th staging (AUC 0.625, 95\% CI: 0.593-0.653)
$(\mathrm{P}<0.001)$ (Figure 1).

\section{Survival analysis}

With a median follow-up time of 49 months (range, 0-83 months), the 5-year BCSS was $97.6 \%$. Patients who received BCS + RT had better 5-year BCSS compared to those treated with MAST in the entire group $(98.3 \% v s$. $96.9 \%, \mathrm{P}<0.001$ ) (Figure 2). When stratifying according to the stage, in the 7th AJCC system, BCS + RT had better 5 -year BCSS than MAST in stage IA (98.9\% vs. $98.0 \%$, $\mathrm{P}<0.001)$ (Figure $3 A$ ) and stage IIA $(96.4 \%$ vs. $94.7 \%$, $\mathrm{P}=0.039$ ) diseases (Figure $3 B$ ). In the 8th AJCC staging criterion, BCS + RT could improve 5-year BCSS compared with MAST in patients with stage IA $(99.3 \%$ vs. $98.7 \%$, $\mathrm{P}=0.006)$ (Figure $4 A$ ) and stage IB $(96.2 \%$ vs. $92.4 \%$, $\mathrm{P}=0.001$ ) (Figure $4 B$ ) diseases, while comparable BCSS was found between BCS + RT and MAST in patients with stage IIA disease $(92.5 \%$ vs. $91.3 \%, \mathrm{P}=0.366)$ (Figure $4 C$ ).

\section{Prognostic factors}

Cox proportional hazards models were conducted to analyze the independent prognostic factors associated with BCSS. The result showed that $\mathrm{T}$ stage $(\mathrm{P}<0.001)$, race/ethnicity $(<0.001)$, tumor grade $(\mathrm{P}<0.001)$, ER status $(\mathrm{P}=0.002)$, PR status $(\mathrm{P}<0.001)$, HER2 status $(\mathrm{P}<0.001)$, and surgical approach $(\mathrm{P}<0.001)$ were the independent prognostic factors for BCSS (Table 2). The 8th AJCC staging system was also an independent prognostic factor for BCSS (Table 3). After adjusting tumor grade, ER status, PR status, and HER2 status in the 7th AJCC staging system, patients who received MAST had inferior BCSS compared to those treated with BCS + RT in stage IA [hazard ratio (HR) 1.741, 95\% CI: $1.297-2.338, \mathrm{P}<0.001]$ and stage IIA (HR 1.342, 95\% CI: 1.017-1.769, P=0.037) diseases (Table 4). In the 8th AJCC staging, patients who received MAST was also had inferior BCSS than those treated with BCS + RT in stage IA (HR 1.601, 95\% CI: 1.125-2.278, P=0.009) and stage IB (HR 1.827, 95\% CI: 1.234-2.704, $\mathrm{P}=0.003$ ) disease, while similar BCSS was found between BCS + RT and MAST groups in stage IIA (HR 1.265, 95\% CI: 0.919-1.741, $\mathrm{P}=0.149$ ) disease (Table 4).

\section{Discussion}

In this study, we aimed to assess the prognostic and predictive value of the 8th AJCC staging system in patients 

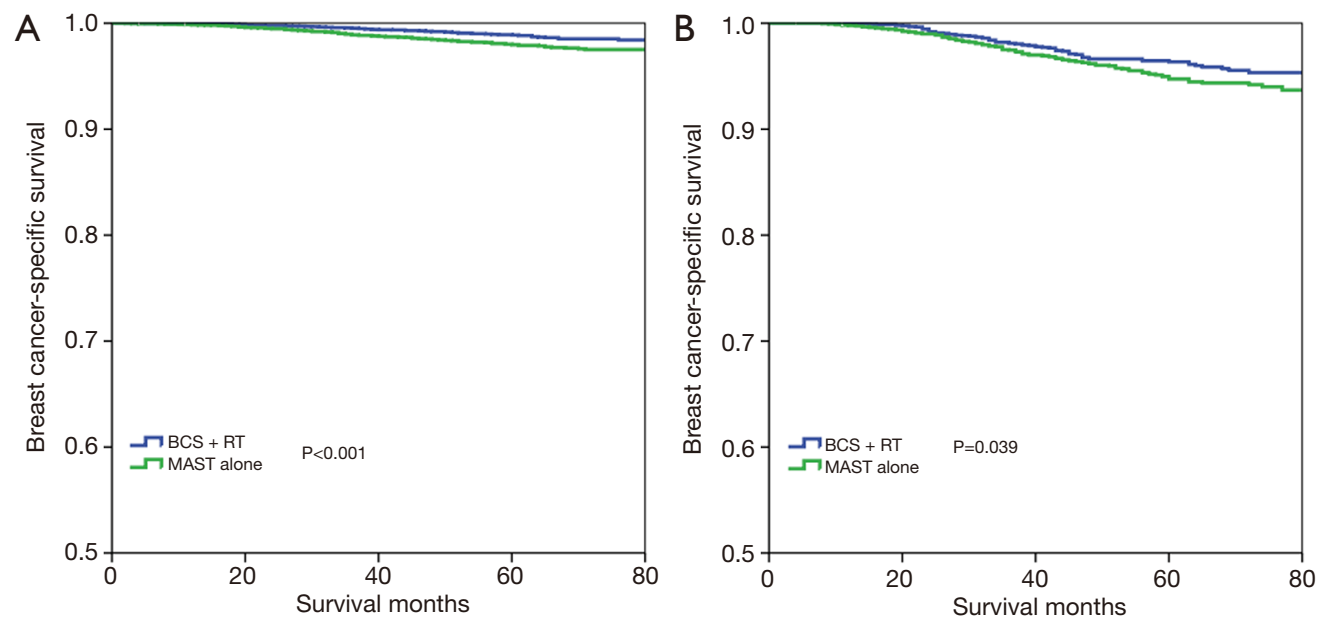

Figure 3 Survival curves between breast-conserving surgery (BCS) + radiotherapy (RT) and mastectomy (MAST) groups in stage IA (A) and IIA (B) in the 7 th American Joint Committee on Cancer staging system.
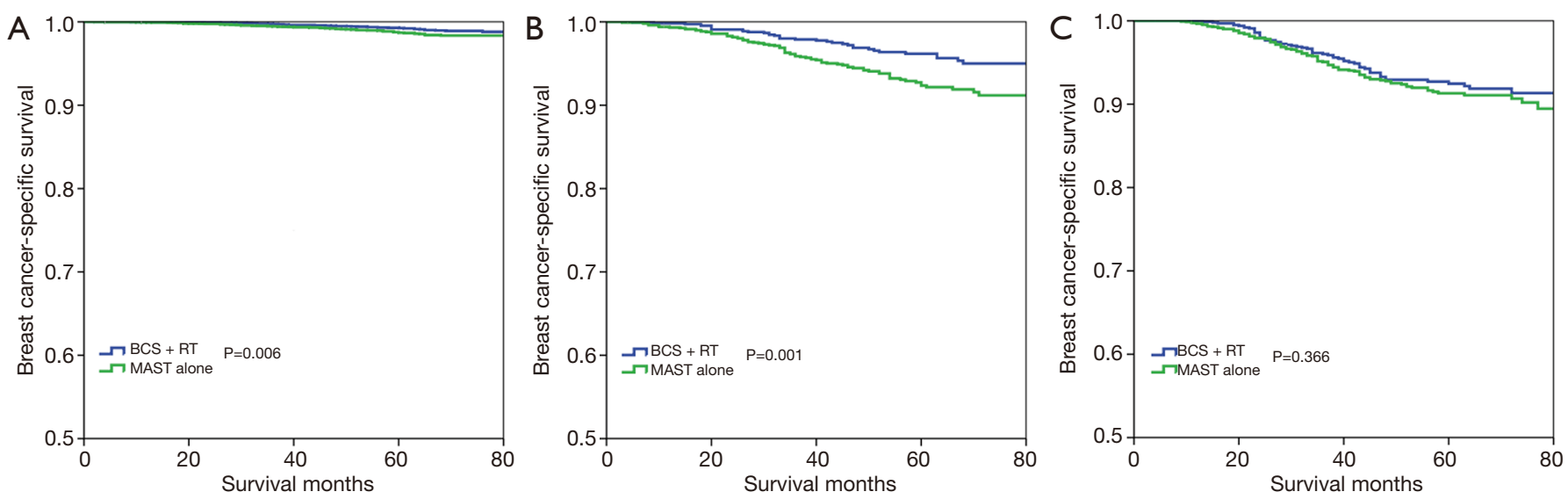

Figure 4 Survival curves between breast-conserving surgery (BCS) + radiotherapy (RT) and mastectomy (MAST) groups in stage IA (A), IB (B), and IIA (C) in the 8th American Joint Committee on Cancer staging system.

with T1-2N0 breast cancer aged $<50$ years, and our findings demonstrated that the new pathological prognostic staging system had a better staging system compared to the conventional anatomic system. In addition, BCS + RT achieved better 5-year BCSS than MAST in stage IA and stage IB diseases, while comparable BCSS found between the two treatment arms in stage IIA disease. Our study was the first to assess the effect of surgical approach selection using the 8 th pathological staging criterion in young breast cancer with T1-2N0 disease.

The further understanding of biomarkers of breast cancer is closely relationship to treatment decision-making (22-24). The 8th edition of the AJCC pathological staging system, which incorporated anatomical information, pathological finding, and biological markers (ER, PR, and HER2 status), was initially established using the information of 305,519 patients from the National Cancer Database in 2018 (25). Several studies have validated the superior prognostic accuracy of the 8th AJCC pathological staging compared to the 7 th anatomical staging $(6,26,27)$. However, limited studies focused on the effect of the 8th AJCC manual in patients with stage T1-2N0 disease. In this study with a large sample size $(n=22,640)$, approximately $25 \%$ of the patients upstaged or downstaged from the 7th AJCC staging to the 8th AJCC staging, and the 8th AJCC staging system performed well discriminatory ability in concordance with 
Table 2 Multivariate analysis of prognostic factors for breast cancer-specific survival in the entire group

\begin{tabular}{|c|c|c|c|}
\hline Variables & HR & $95 \% \mathrm{Cl}$ & $\mathrm{P}$ \\
\hline \multicolumn{4}{|l|}{ Age (years) } \\
\hline$<40$ & 1.000 & & \\
\hline$\geq 40$ & 0.978 & $0.785-1.219$ & 0.844 \\
\hline \multicolumn{4}{|l|}{ Race/ethnicity } \\
\hline Non-Hispanic White & 1.000 & & \\
\hline Non-Hispanic Black & 1.520 & $1.199-1.927$ & $<0.001$ \\
\hline Hispanic & 0.782 & $0.578-1.058$ & 0.111 \\
\hline Other & 0.575 & $0.389-0.851$ & 0.006 \\
\hline \multicolumn{4}{|l|}{ Grade } \\
\hline Well differentiated & 1.000 & & \\
\hline Moderately differentiated & 4.027 & $2.084-7.779$ & $<0.001$ \\
\hline $\begin{array}{l}\text { Poorly differentiated/ } \\
\text { undifferentiated }\end{array}$ & 9.949 & $5.167-19.154$ & $<0.001$ \\
\hline \multicolumn{4}{|l|}{ T stage } \\
\hline $\mathrm{T} 1$ & 1.000 & & \\
\hline $\mathrm{T} 2$ & 1.584 & $1.300-1.929$ & $<0.001$ \\
\hline \multicolumn{4}{|l|}{ ER status } \\
\hline Negative & 1.000 & & \\
\hline Positive & 0.629 & $0.471-0.841$ & 0.002 \\
\hline \multicolumn{4}{|l|}{ PR status } \\
\hline Negative & 1.000 & & \\
\hline Positive & 0.574 & $0.422-0.781$ & $<0.001$ \\
\hline \multicolumn{4}{|l|}{ HER2 status } \\
\hline Negative & 1.000 & & \\
\hline Positive & 0.566 & $0.425-0.755$ & $<0.001$ \\
\hline \multicolumn{4}{|l|}{ Surgical approach } \\
\hline $\mathrm{BCS}+\mathrm{RT}$ & 1.000 & & \\
\hline MAST alone & 1.470 & $1.200-1.801$ & $<0.001$ \\
\hline
\end{tabular}

$\mathrm{HR}$, hazard ratio; $\mathrm{Cl}$, confidence interval; $\mathrm{ER}$, estrogen receptor; PR, progesterone receptor; HER2, human epidermal growth factor receptor 2; BCS, breast-conserving surgery; RT, radiotherapy; MAST, mastectomy.

the stage. Therefore, the new AJCC staging criterion could better guide the individualized management and prognosis evaluation in T1-2N0 patients.

The decision of surgical procedure in patients with
Table 3 Multivariate analysis of prognostic factors for breast cancer-specific survival in the whole group

\begin{tabular}{llll}
\hline Variables & $\mathrm{HR}$ & $95 \% \mathrm{Cl}$ & $\mathrm{P}$ \\
\hline Age (years) & & & \\
$<40$ & 1.000 & & \\
$\geq 40$ & 0.928 & $0.745-1.157$ & 0.506
\end{tabular}

Race/ethnicity

Non-Hispanic White 1.000

Non-Hispanic Black

1.637

$1.291-2.076<0.001$

Hispanic

0.787

$0.582-1.065$

0.121

Other

$\begin{array}{lll}0.567 & 0.384-0.839 & 0.005\end{array}$

T stage

T1

1.000

T2

0.778

$0.578-1.046$

0.097

The 8th AJCC staging

IA

IB

IIA

1.000

5.989

4.649-7.716 $<0.001$

9.589

$6.787-13.546<0.001$

Surgical approach

\begin{tabular}{llll} 
BCS + RT & 1.000 & & \\
MAST alone & 1.527 & $1.247-1.870$ & $<0.001$ \\
\hline
\end{tabular}

$\mathrm{HR}$, hazard ratio; $\mathrm{Cl}$, confidence interval; BCS, breastconserving surgery; RT, radiotherapy; MAST, mastectomy; AJCC, American Joint Committee on Cancer.

T1-2N0 breast cancer has been well elaborated in the 7th AJCC staging system, and BCS + RT had at least comparable survival compared to MAST in patients with early breast cancer $(8,10,11,13,14)$. However, the surgical selection building upon the 8th AJCC manual was unclear. Almost all patients who established the 8th AJCC manual received systemic therapy. Thus, the effect of locoregional treatment should be validated before it was applied to clinical practice. In our study, BCS + RT achieved a better BCSS rate than MAST in T1-2N0 patients aged $<50$ years using traditional anatomical staging. When using the 8 th pathological staging, BCS + RT had better BCSS compared with MAST in stage IA and IB diseases, while comparable survival was found in stage IIA diseases between the two treatment arms. Therefore, patients with stage IIA disease should be individually managed when applying an updated staging system. For pregnancy-associated breast cancer, 
Table 4 Sensitivity analysis of the effect of surgical approach on prognosis after stratification by the 7 th and the 8 th AJCC staging

\begin{tabular}{lccc}
\hline Variables & HR & $95 \% \mathrm{Cl}$ & $\mathrm{P}$ \\
\hline $\begin{array}{l}\text { The 7th AJCC staging } \\
\text { Stage IA }\end{array}$ & & & \\
BCS + RT & 1.000 & & \\
MAST alone & 1.741 & $1.297-2.338$ & $<0.001$ \\
Stage IIA & & & \\
BCS + RT & 1.000 & & \\
MAST alone & 1.342 & $1.017-1.769$ & 0.037 \\
The 8th AJCC staging & & & \\
Stage IA & & & \\
BCS + RT & 1.000 & & \\
MAST alone & 1.601 & $1.125-2.278$ & 0.009 \\
Stage IB & & & \\
BCS + RT & 1.000 & & \\
MAST alone & 1.827 & $1.234-2.704$ & 0.003 \\
Stage IIA & & & \\
BCS + RT & 1.000 & & \\
MAST alone & & & \\
\hline H hazard ratio; Cl, con & & & \\
\end{tabular}

$\mathrm{HR}$, hazard ratio; $\mathrm{Cl}$, confidence interval; $\mathrm{BCS}$, breastconserving surgery; RT, radiotherapy; MAST, mastectomy; AJCC, American Joint Committee on Cancer.

claustrophobia patients, patients refusing breast radiation or unable to tolerate RT, and institutions without RT equipment, MAST could be an optional choice for patients with stage IIA disease (28).

Among the patients in this study, $46.2 \%$ of them received the BCS + RT procedure, which was significantly lower than previous studies in patients of all ages (56.3$57.3 \%)(29,30)$. We demonstrated that patients with adverse prognostic factors such as large tumor size, ER/ PR negative, and HER2 positive, were associated with increased rates of MAST, and the result was similar to prior studies $(29,30)$. Although the receipt of BCS had an upward trend over time (29), the possibility of the receipt of BCS was still lower than MAST. Several studies have suggested that patients undergoing BCS have more advantages than patients undergoing MAST, including faster recovery (31), better compliance for postoperative medical surveillance and follow-up by surgeon teams (32), better sexual well- being and life satisfaction $(33,34)$. Therefore, according to our findings, BCS + RT was the optimal local treatment for breast cancer patients at a young age.

Several potential limitations should be acknowledged in this study. Firstly, the data in our study was extracted from the SEER database, and selection biases in the retrospective study were inevitable. Secondly, the SEER database lacks sufficient details about systemic therapy (chemotherapy protocol, endocrine therapy, and anti-HER2 targeted therapies), radiation therapy (RT technique, RT dose, and target volume). In addition, the patterns of locoregional recurrence and distant metastasis were also not recorded in the SEER database. Finally, the follow-up period might be relatively short in this study due to the better survival in patients with T1-2N0 breast cancer. The primary strength of our study was that we detailedly verify the effect of BCS + RT and MAST with a large sample size of 22,640 patients in early breast cancer based on the 8th AJCC staging system.

\section{Conclusions}

In conclusion, our study demonstrated that the 8th AJCC pathological staging system had better prognostic accuracy than the 7 th anatomical staging. In addition, in terms of surgical decision-making, BCS + RT was still the standard treatment for stage IA and IB, while it was optional management in stage IIA in patients with T1-2N0 breast cancer aged $<50$ years in the basis of the 8 th AJCC staging.

\section{Acknowledgments}

The authors acknowledge the efforts of the Surveillance, Epidemiology, and End Results (SEER) Program tumor registries in the creation of the SEER database.

Funding: This work was partly supported by the National Natural Science Foundation of China (No. 81872459) and the Commission Young and Middle-aged Talents Training Project of Fujian Health Commission (No. 2019-ZQNB25).

\section{Footnote}

Reporting Checklist: The authors have completed the STROBE reporting checklist. Available at http://dx.doi. org/10.21037/gs-20-587

Conflicts of Interest: All authors have completed the ICMJE 
uniform disclosure form (available at http://dx.doi. org/10.21037/gs-20-587). The authors have no conflicts of interest to declare.

Ethical Statement: The authors are accountable for all aspects of the work in ensuring that questions related to the accuracy or integrity of any part of the work are appropriately investigated and resolved. The approval process of Institutional Review Board was waived because of the de-identified information of the patients included in the SEER. The study was conducted in accordance with the Declaration of Helsinki (as revised in 2013).

Open Access Statement: This is an Open Access article distributed in accordance with the Creative Commons Attribution-NonCommercial-NoDerivs 4.0 International License (CC BY-NC-ND 4.0), which permits the noncommercial replication and distribution of the article with the strict proviso that no changes or edits are made and the original work is properly cited (including links to both the formal publication through the relevant DOI and the license). See: https://creativecommons.org/licenses/by-nc-nd/4.0/.

\section{References}

1. Bray F, Ferlay J, Soerjomataram I, et al. Global cancer statistics 2018: GLOBOCAN estimates of incidence and mortality worldwide for 36 cancers in 185 countries. CA Cancer J Clin 2018;68:394-424.

2. Moossdorff M, Nakhlis F, Hu J, et al. The Potential Impact of AMAROS on the Management of the Axilla in Patients with Clinical T1-2N0 Breast Cancer Undergoing Primary Total Mastectomy. Ann Surg Oncol 2018;25:2612-9.

3. van Maaren MC, Strobbe LJA, et al. Ten-year conditional recurrence risks and overall and relative survival for breast cancer patients in the Netherlands: Taking account of event-free years. Eur J Cancer 2018;102:82-94.

4. Gospodarowicz MK, Brierley JD, Wittekind C. TNM Classification of Malignant Tumours. Chichester: Wiley, 2017.

5. Harris LN, Ismaila N, McShane LM, et al. Use of Biomarkers to Guide Decisions on Adjuvant Systemic Therapy for Women with Early-Stage Invasive Breast Cancer: American Society of Clinical Oncology Clinical Practice Guideline. J Clin Oncol 2016;34:1134-50.

6. Wang M, Chen $\mathrm{H}$, Wu K, et al. Evaluation of the prognostic stage in the 8th edition of the American
Joint Committee on Cancer in locally advanced breast cancer: An analysis based on SEER 18 database. Breast 2018;37:56-63.

7. Clarke M, Collins R, Darby S, et al. Effects of radiotherapy and of differences in the extent of surgery for early breast cancer on local recurrence and 15 -year survival: an overview of the randomised trials. Lancet 2005;366:2087-106.

8. Arndt V, Stegmaier C, Ziegler H, et al. Quality of life over 5 years in women with breast cancer after breastconserving therapy versus mastectomy: a population-based study. J Cancer Res Clin Oncol 2008;134:1311-8.

9. Bertozzi N, Pesce M, Santi PL, et al. Oncoplastic breast surgery: comprehensive review. Eur Rev Med Pharmacol Sci 2017;21:2572-85.

10. Agarwal S, Pappas L, Neumayer L, et al. Effect of breast conservation therapy vs mastectomy on diseasespecific survival for early-stage breast cancer. JAMA Surg 2014;149:267-74.

11. Veronesi U, Cascinelli N, Mariani L, et al. Twentyyear follow-up of a randomized study comparing breastconserving surgery with radical mastectomy for early breast cancer. N Engl J Med 2002;347:1227-32.

12. McCloskey SA, Botnick LE, Rose CM, et al. Longterm outcomes after breast conservation therapy for early stage breast cancer in a community setting. Breast $\mathrm{J}$ 2006;12:138-44.

13. Fisher B, Anderson S, Bryant J, et al. Twenty-year followup of a randomized trial comparing total mastectomy, lumpectomy, and lumpectomy plus irradiation for the treatment of invasive breast cancer. $\mathrm{N}$ Engl J Med 2002;347:1233-41.

14. Early Breast Cancer Trialists' Collaborative Group (EBCTCG); Darby S, McGale P, et al. Effect of radiotherapy after breast-conserving surgery on 10year recurrence and 15-year breast cancer death: metaanalysis of individual patient data for 10,801 women in 17 randomised trials. Lancet 2011;378:1707-16.

15. Arvold ND, Taghian AG, Niemierko A, et al. Age, breast cancer subtype approximation, and local recurrence after breast-conserving therapy. J Clin Oncol 2011;29:3885-91.

16. Maishman T, Cutress RI, Hernandez A, et al. Local Recurrence and Breast Oncological Surgery in Young Women with Breast Cancer: The POSH Observational Cohort Study. Ann Surg 2017;266:165-72.

17. Teo SY, Chuwa E, Latha S, et al. Young breast cancer in a specialised breast unit in Singapore: clinical, radiological and pathological factors. Ann Acad Med Singapore 
2014;43:79-85.

18. Bhoo-Pathy N, Subramaniam S, Taib NA, et al. Spectrum of very early breast cancer in a setting without organised screening. Br J Cancer 2014;110:2187-94.

19. Laurberg T, Lyngholm CD, Christiansen P, et al. Long-term age-dependent failure pattern after breastconserving therapy or mastectomy among Danish lymphnode-negative breast cancer patients. Radiother Oncol 2016;120:98-106.

20. Vila J, Gandini S, Gentilini O. Overall survival according to type of surgery in young ( $\leq 40$ years) early breast cancer patients: A systematic metaanalysis comparing breast-conserving surgery versus mastectomy. Breast 2015;24:175-81.

21. Noone AM, Lund JL, Mariotto A, et al. Comparison of SEER Treatment Data With Medicare Claims. Med Care 2016;54:e55-64.

22. Cancer Genome Atlas Network. Comprehensive molecular portraits of human breast tumours. Nature 2012;490:61-70.

23. Sørlie T, Perou CM, Tibshirani R, et al. Gene expression patterns of breast carcinomas distinguish tumor subclasses with clinical implications. Proc Natl Acad Sci U S A 2001;98:10869-74.

24. Yi M, Mittendorf EA, Cormier JN, et al. Novel staging system for predicting disease-specific survival in patients with breast cancer treated with surgery as the first intervention: time to modify the current American Joint Committee on Cancer staging system. J Clin Oncol 2011;29:4654-61

25. AJCC cancer staging manual. New York: Springer International Publishing, 2018.

26. Giuliano AE, Connolly JL, Edge SB, et al. Breast CancerMajor changes in the American Joint Committee on

Cite this article as: Wang J, Lian CL, Zhou P, Lei J, Hua L, He ZY, Wu SG. The prognostic and predictive value of the 8 th American Joint Committee on Cancer (AJCC) staging system among early breast cancer patients aged $<50$ years. Gland Surg 2021;10(1):233-241. doi: 10.21037/gs-20-587
Cancer eighth edition cancer staging manual. CA Cancer J Clin 2017;67:290-303.

27. Shao N, Xie C, Shi Y, et al. Comparison of the 7th and 8th edition of American Joint Committee on Cancer (AJCC) staging systems for breast cancer patients: a Surveillance, Epidemiology and End Results (SEER) Analysis. Cancer Manag Res 2019;11:1433-42.

28. Alfasi A, Ben-Aharon I. Breast Cancer during PregnancyCurrent Paradigms, Paths to Explore. Cancers (Basel) 2019;11:1669.

29. Lagendijk M, van Maaren MC, Saadatmand S, et al. Breast conserving therapy and mastectomy revisited: Breast cancer-specific survival and the influence of prognostic factors in 129,692 patients. Int J Cancer 2018;142:165-75.

30. Chen K, Pan Z, Zhu L, et al. Comparison of breastconserving surgery and mastectomy in early breast cancer using observational data revisited: a propensity scorematched analysis. Sci China Life Sci 2018;61:1528-36.

31. Retsky M, Demicheli R, Hrushesky WJ, et al. Reduction of breast cancer relapses with perioperative non-steroidal anti-inflammatory drugs: new findings and a review. Curr Med Chem 2013;20:4163-76.

32. Gu J, Groot G, Boden C, et al. Review of Factors Influencing Women's Choice of Mastectomy Versus Breast Conserving Therapy in Early Stage Breast Cancer: A Systematic Review. Clin Breast Cancer 2018;18:e539-54.

33. Cipora E, Konieczny M, Karwat ID, et al. Surgical method of treatment and level of satisfaction with life among women diagnosed with breast cancer, according to time elapsed since performance of surgery. Ann Agric Environ Med 2018;25:453-9.

34. Klassen AF, Pusic AL, Scott A, et al. Satisfaction and quality of life in women who undergo breast surgery: a qualitative study. BMC Womens Health 2009;9:11. 